\title{
Vibrational Modal Frequencies and Shapes of Two-Span Continuous Timber Flooring Systems
}

\author{
Binsheng Zhang (iD and Tony Kilpatrick \\ Department of Civil Engineering and Environmental Management, School of Computing, Engineering and Built Environment, \\ Glasgow Caledonian University, Glasgow G4 OBA, UK \\ Correspondence should be addressed to Binsheng Zhang; ben.zhang@gcu.ac.uk
}

Received 16 September 2018; Accepted 10 April 2019; Published 28 April 2019

Academic Editor: Zhixiong Li

Copyright (c) 2019 Binsheng Zhang and Tony Kilpatrick. This is an open access article distributed under the Creative Commons Attribution License, which permits unrestricted use, distribution, and reproduction in any medium, provided the original work is properly cited.

\begin{abstract}
Based on classic vibrational bending theory on beams, this paper provides comprehensive analytical formulae for dynamic characteristics of two equal span continuous timber flooring systems, including frequency equations, modal frequencies, and modal shapes. Four practical boundary conditions are considered for end supports, including free, sliding, pinned, and fixed boundaries, and a total of sixteen combinations of flooring systems are created. The deductions of analytical formulae are also expanded to two unequal span continuous flooring systems with pinned end supports, and empirical equations for obtaining the fundamental frequency are proposed. The acquired analytical equations for vibrational characteristics can be applied for practical design of two-span continuous flooring systems. Two practical design examples are provided as well.
\end{abstract}

\section{Introduction}

Vibrational serviceability performance of timber floors has become an important issue in the world due to their resonance frequencies and low material masses. In Europe, Eurocode 5 [1] has been widely used for design of timber floors to satisfy serviceability limit state criteria [2], in particular vibrations, because they are often governing the design of timber floors. The fundamental frequency, unit point load deflection, and unit impulse velocity response as the key vibrational parameters need to be checked. The methods for obtaining these parameters and their limits are presented in EN 1995 Part 1-1 [2] and the National Annexes of individual European countries [3].

Human beings are considered as precarious sensors of vibrations, and their distress to timber floor vibrations concern many researchers, and human activities and machine-induced vibrations can cause distress. Human sensitivity and perception are basically related to structural vibrations.

\section{Previous Research Studies on Timber Floor Vibration}

Over past decades, extensive investigations have been conducted on evaluating the dynamic performance of timber floors and human vibrational perception in many European countries, Canada, Australia, and Japan. Ohlsson [4] investigated human-induced vibrations by testing a number of timber floors, and his work has been implemented in Eurocode 5 for timber floor design [1]. Chui [5] proposed use of the root mean square (r.m.s.) acceleration for design based on his field tests on timber floors and. $\mathrm{Hu}$ [6] dynamically tested $I$-joist floors and numerically simulated the vibrational behaviour of these floors. Eriksson [7] measured the dynamic forces of low frequencies caused by walking, running, and jumping. Smith [8] explored the vibrational issues for timber floors. Bahadori-Jahromi et al. [9, 10] innovated timber floors with multiwebbed joists and conducted static and dynamic tests on these floors. Homb [11] assessed human perception based on the results of impact-induced low frequency vibrations on timber floors. 
Ljunggren [12] assessed the dependence of human perception on the dynamic properties of lightweight steel framed floors. Toratti and Talja [13] established body perception scales to reflect the significant dependence of disturbance on different vibrational sources. Zhang et al. $[14,15]$ systematically assessed the effects of influencing parameters on the vibrational performance of timber floors constructed with various joists. Weckendorf [16] measured the vibrational characteristics of $I$-joist timber floors. Labonnote [17] categorised damping in timber components. Zhang et al. [18, 19] assessed the vibrational responses of timber floors constructed with metal web joists by altering structural configurations. Jarnerö et al. [20] measured the dynamic characteristics of a prefabricated timber floor with various boundary conditions at different construction stages. Two textbooks were also written on structural timber design to Eurocode 5 [21, 22].

Recently, considerable attention has been paid to the dynamic responses of timber floors constructed with LVL (laminated veneer lumber) beams, glulam beams and CLT (cross-laminated timber) panels, and TCC (timberconcrete composite) floors. Basaglia et al. [23] assessed the vibrational measures on timber floors and compared the design criteria between Australia and Japan by testing a $9 \mathrm{~m}$ span LVL ribbed-deck cassette floor. Ebadi et al. [24] explored the vibrational response of glulam floors. Ui Chulain and Harte [25] investigated the influence of modern timber fixing systems and extra mass on the serviceability behaviour of one-way or two-way CLT floors in laboratory. Koyama et al. [26] measured the vibrational characteristics of a CLT floor subjected to walking vibrations. Bui et al. [27] experimentally investigated the natural frequencies, damping ratios, and mode shapes of multilayered timber beams. Lanata et al. [28] attempted to establish correlations between the dynamic response of in situ timber and TCC floors and human comfort perception by varying building typology.

2.1. Design Codes in European Countries. EN 1995-1-1 [1] has adopted three parameters proposed by Ohlsson [4] for controlling the vibrational serviceability design of timber flooring systems. For residential floors which are simply supported along all four edges, it requires that the fundamental frequency or the lowest first-order modal frequency $f_{1}$ in $\mathrm{Hz}$ should satisfy the following equation:

$$
f_{1}=\frac{\pi}{2 L^{2}} \sqrt{\frac{(E I)_{L}}{m}}>8 \mathrm{~Hz}
$$

where $L$ is the floor span in $\mathrm{m},(E I)_{L}$ is the equivalent plate bending stiffness of the floor about an axis perpendicular to the beam direction in $\mathrm{Nm}^{2} / \mathrm{m}$, and $m$ is the mass per unit area in $\mathrm{kg} / \mathrm{m}^{2}$. Equation (1) is a simplified design equation which is actually applied for two-side supported floors, and the effect of the transverse stiffness is omitted because of small errors caused. EN 1995-1-1 does not clearly indicate how the participating mass should be calculated and whether the composite effect of floor joists and deck in the floor direction should be considered. The design equations and the corresponding limits for $f_{1}$ proposed from EN 1995-1-1 and various National Annexes in European countries have been previously summarised [3].

The majority of European countries have directly adopted equation (1) and the limit of $8 \mathrm{~Hz}$ specified in EN 1995-1-1 [29]. However, Austria [30] only adopts equation (1) for two-side supported floors and provides a fairly accurate equation for four-side supported floors by including a quartic term about the floor span to width ratio, $L / B$, to reflect the effect of the transverse stiffness as

$$
f_{1}=\frac{\pi}{2 L^{2}} \sqrt{\frac{(E I)_{L}}{m}} \sqrt{1+\left(\frac{L}{B}\right)^{4} \frac{(E I)_{B}}{(E I)_{L}}} .
$$

Similarly, Finland [31] provides a more accurate equation for four-side supported floors by including both second- and fourth-order terms about $L / B$ for the effect of the transverse stiffness with a raised frequency limit of $9 \mathrm{~Hz}$ as

$$
f_{1}=\frac{\pi}{2 L^{2}} \sqrt{\frac{(E I)_{L}}{m}} \sqrt{1+\left(2\left(\frac{L}{B}\right)^{2}+\left(\frac{L}{B}\right)^{4}\right) \frac{(E I)_{B}}{(E I)_{L}}}
$$

Both Austria and Finland specify that the floor mass $m$ should be determined by using a quasipermanent combination of dead and imposed loads, as specified in EN 1990 [2]:

$$
m=m_{G_{\mathrm{k}}}+\psi_{2} m_{Q_{\mathrm{k}}}
$$

where $m_{G_{\mathrm{k}}}$ is the mass due to the characteristic dead load $G_{\mathrm{k}}$ and $m_{Q_{k}}$ is the mass due to the characteristic imposed load $Q_{k} \cdot \psi_{2}$ is the factor for quasipermanent value of a variable action, and its values for different building categories can be taken from the relevant tables of EN 1990 [2] or the National Annexes to EN 1990. In general, $\psi_{2}$ can be taken as 0.3 for residential and office buildings, 0.6 for congregation areas, and 0.8 for storage areas.

Spain [32] limits the values for the fundamental frequency $f_{1}$ for all construction materials including timber. More recently, Hu et al. [33] attempted to develop a baseline vibration design method for timber floors by combining all available databases in the world so as to eventually develop an ISO standard. The future work will be to harmonise the calculation methods and to rederive the baseline design criterion by using the collective floor database.

2.2. Significance of Current Research. With the development of engineered timber products, floor joist sizes can be manufactured much larger for longer floor spans or multispans. Some research work on structural dynamic characteristics of general continuous beams has been reported [34, 35]. The information for determining vibrational characteristics of continuous timber flooring systems, however, is still limited. In this paper, the characteristic equations for modal frequencies and shapes of continuous floors of two equal spans with various boundary conditions or floors of two unequal spans with pinned boundary conditions are deduced. Two design examples of two-span timber flooring systems are also presented. 


\section{Equations of Motion for Two-Span Continuous Floors}

For two-span continuous timber flooring systems with equal joist spacing but various end supports, they can be treated as two-span beams and analysed on a single two-span continuous timber floor joist (see Figure 1 in which $0 \leq x_{1} \leq L_{1}$ and $0 \leq x_{2} \leq L_{2}$ ).

3.1. Equations of Motion. For a two-span continuous Bernoulli-Euler beam with a uniform cross-sectional area, mass density, and flexural stiffness, the equation of motion for each beam span, i.e., transverse displacement $y_{i}\left(x_{i}, t\right)$ versus time $t$ for span $i$, is given as

$$
E I \frac{\partial^{4} y_{i}}{\partial x_{i}^{4}}+c \frac{\partial y_{i}}{\partial t}+\rho A \frac{\partial^{2} y_{i}}{\partial t^{2}}=f_{i}\left(x_{i}, t\right)
$$

where $E I$ is the flexural stiffness, $c$ is the viscous damping coefficient, $\rho$ is the mass density per unit volume, $A$ is the cross-sectional area, $f_{i}\left(x_{i}, t\right)$ is the time varying external load, and $i$ is the span number $(i=1,2)$ [36]. Assume $y_{i}\left(x_{i}, t\right)$ can be separated for $x_{i}$ and $t$ as

$$
y_{i}\left(x_{i}, t\right)=y_{i}\left(x_{i}\right) g(t)
$$

Substituting equation (6) in equation (5) and ignoring the harmonic part yields the homogeneous solutions as

$$
\begin{aligned}
y_{i}\left(x_{i}\right)= & C_{i 1} \sin \beta x_{i}+C_{i 2} \cos \beta x_{i}+C_{i 3} \sinh \beta x_{i} \\
& +C_{i 4} \cosh \beta x_{i} .
\end{aligned}
$$

The natural frequencies and coefficients $C_{i 1}$ to $C_{i 4}$ of the beam can be obtained by applying appreciate boundary conditions. The natural frequencies $f_{n}$ are determined as

$$
f_{n}=\frac{\omega_{n}}{2 \pi}=\frac{\beta_{n}^{2}}{2 \pi} \sqrt{\frac{E I}{\rho A}}=\frac{\left(\beta_{n} L_{1}\right)^{2}}{2 \pi L_{1}^{2}} \sqrt{\frac{(E I)_{L}}{m}},
$$

where $\omega_{n}$ is the circular modal frequency for $n^{\text {th }}$ mode in $\mathrm{rad} / \mathrm{sec},(E I)_{L}$ is the equivalent plate bending stiffness of the timber floor about an axis perpendicular to the beam direction in $\mathrm{Nm}^{2} / \mathrm{m}$ and $(E I)_{L}$ is given as $(E I)_{\text {joist }} / s,(E I)_{\text {joist }}$ is the flexural stiffness of the floor joist in $\mathrm{Nm}^{2}, s$ is the floor joist spacing in $\mathrm{m}$, and $m$ is the mass per unit area in $\mathrm{kg} / \mathrm{m}^{2}$.

3.2. Boundary Conditions. Four typical boundary conditions for two-span continuous beams are considered with various end supports, e.g., free, sliding, pinned, and fixed boundaries (Table 1), which forms sixteen combinations of flooring systems.

\section{Vibrations for Continuous Floors with Two Equal Spans}

For continuous timber flooring systems with two equal spans, $L_{1}=L_{2}=L$.

4.1. Frequency Equations. To establish the frequency equations of two equal span flooring systems and to determine

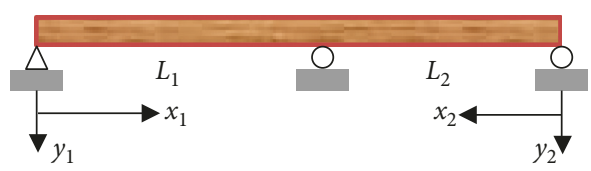

Figure 1: A typical two-span continuous timber floor.

TABle 1: Boundary conditions for two-span continuous beams.

\begin{tabular}{lc}
\hline $\begin{array}{l}\text { Boundary } \\
\text { conditions }\end{array}$ & Control equations \\
\hline Free end & $d^{2} y_{i} / d x_{i}^{2}\left(x_{i}=0\right)=0, d^{3} y_{i} / d x_{i}^{3}\left(x_{i}=0\right)=0$ \\
Sliding end & $d y_{i} / d x_{i}\left(x_{i}=0\right)=0, d^{3} y_{i} / d x_{i}^{3}\left(x_{i}=0\right)=0$ \\
Pinned end & $y_{i}\left(x_{i}=0\right)=0, d^{2} y_{i} / d x_{i}^{2}\left(x_{i}=0\right)=0$ \\
Fixed end & $y_{i}\left(x_{i}=0\right)=0, d y_{i} / d x_{i}\left(x_{i}=0\right)=0$ \\
Pinned middle & $y_{1}\left(x_{1}=L_{1}\right)=0, y_{2}\left(x_{2}=L_{2}\right)=0$, \\
support & $d y_{1} / d x_{1}\left(x_{1}=L_{1}\right)=-d y_{2} / d x_{2}\left(x_{2}=L_{2}\right)$, \\
& $d^{2} y_{1} / d x_{1}^{2}\left(x_{1}=L_{1}\right)=d^{2} y_{2} / d x_{2}^{2}\left(x_{2}=L_{2}\right)$ \\
\hline
\end{tabular}

the modal frequencies and mode shapes, the displacement equation (7) should be used in conjunction with the boundary conditions listed in Table 1 . To demonstrate the procedure, a typical two equal span continuous beam with left end fixed and right end simply supported is used here (Figure 2).

For spans 1 and 2, equation (7) can be rewritten as

$$
\begin{aligned}
y_{1}\left(x_{1}\right)= & C_{11} \sin \beta x_{1}+C_{12} \cos \beta x_{1}+C_{13} \sinh \beta x_{1} \\
& +C_{14} \cosh \beta x_{1}, \\
y_{2}\left(x_{2}\right)= & C_{21} \sin \beta x_{2}+C_{22} \cos \beta x_{2}+C_{23} \sinh \beta x_{2} \\
& +C_{24} \cosh \beta x_{2} .
\end{aligned}
$$

Differentiating equations (9) and (10) for three times yields

$$
\begin{aligned}
\frac{d y_{1}\left(x_{1}\right)}{d x_{1}}= & C_{11} \beta \cos \beta x_{1}-C_{12} \beta \sin \beta x_{1}+C_{13} \beta \cosh \beta x_{1} \\
& +C_{14} \beta \sinh \beta x_{1},
\end{aligned}
$$

$$
\begin{aligned}
\frac{d y_{1}^{2}\left(x_{1}\right)}{d x_{1}^{2}}= & -C_{11} \beta^{2} \sin \beta x_{1}-C_{12} \beta^{2} \cos \beta x_{1}+C_{13} \beta^{2} \sinh \beta x_{1} \\
& +C_{14} \beta^{2} \cosh \beta x_{1},
\end{aligned}
$$

$$
\begin{aligned}
\frac{d y_{1}^{3}\left(x_{1}\right)}{d x_{1}^{2}}= & -C_{11} \beta^{3} \cos \beta x_{1}+C_{12} \beta^{3} \sin \beta x_{1}+C_{13} \beta^{3} \cosh \beta x_{1} \\
& +C_{14} \beta^{3} \sinh \beta x_{1},
\end{aligned}
$$

$$
\begin{aligned}
\frac{d y_{2}\left(x_{2}\right)}{d x_{2}}= & C_{21} \beta \cos \beta x_{2}-C_{22} \beta \sin \beta x_{2}+C_{23} \beta \cosh \beta x_{2} \\
& +C_{24} \beta \sinh \beta x_{2},
\end{aligned}
$$




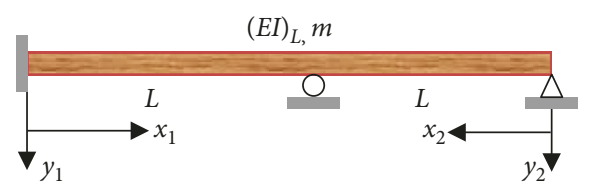

Figure 2: A two equal span continuous timber floor beam with left end fixed and right end simply supported.

$$
\begin{aligned}
\frac{d y_{2}^{2}\left(x_{2}\right)}{d x_{2}^{2}}= & -C_{21} \beta^{2} \sin \beta x_{2}-C_{22} \beta^{2} \cos \beta x_{2}+C_{23} \beta^{2} \sinh \beta x_{2} \\
& +C_{24} \beta^{2} \cosh \beta x_{2},
\end{aligned}
$$

$$
\begin{aligned}
\frac{d y_{2}^{3}\left(x_{2}\right)}{d x_{2}^{2}}= & -C_{21} \beta^{3} \cos \beta x_{2}+C_{22} \beta^{3} \sin \beta x_{2}+C_{23} \beta^{3} \cosh \beta x_{2} \\
& +C_{24} \beta^{3} \sinh \beta x_{2} .
\end{aligned}
$$

\subsubsection{Boundary Conditions for Span 1}

(a) $y_{1}\left(x_{1}\right)=0$ at $x_{1}=0$, so equation (9) degenerates to

$$
\begin{gathered}
y_{1}\left(x_{1}=0\right)=C_{12}+C_{14}=0, \\
\text { or } C_{14}=-C_{12} .
\end{gathered}
$$

(b) $d y_{1}\left(x_{1}\right) / d x_{1}=0$ at $x_{1}=0$, so equation (11) degenerates to

$$
\begin{aligned}
\frac{d y_{1}\left(x_{1}\right)}{d x_{1}} & =C_{11} \beta+C_{13} \beta=0, \\
\text { or } C_{13} & =-C_{11} .
\end{aligned}
$$

Thus, equation (9) becomes

$$
\begin{aligned}
y_{1}\left(x_{1}\right)= & C_{11}\left(\sin \beta x_{1}-\sinh \beta x_{1}\right) \\
& +C_{12}\left(\cos \beta x_{1}-\cosh \beta x_{1}\right) .
\end{aligned}
$$

(c) $y_{1}\left(x_{1}\right)=0$ at $x_{1}=L$, so equation (19) degenerates to $y_{1}\left(x_{1}=L\right)=C_{11}(\sin \beta L-\sinh \beta L)$

$$
\begin{aligned}
& +C_{12}(\cos \beta L-\cosh \beta L)=0, \\
\text { or } C_{12}= & -\frac{(\sin \beta L-\sinh \beta L)}{(\cos \beta L-\cosh \beta L)} C_{11} .
\end{aligned}
$$

\subsubsection{Boundary Conditions for Span 2}

(d) $y_{2}\left(x_{2}\right)=0$ at $x_{2}=0$, so equation (10) degenerates to

$$
\begin{gathered}
y_{2}\left(x_{2}=0\right)=C_{22}+C_{24}=0, \\
\text { or } C_{24}=-C_{22} .
\end{gathered}
$$

(e) $d y_{2}^{2}\left(x_{2}\right) / d x_{2}^{2}=0$ at $x_{2}=0$, so equation (15) degenerates to

$$
\begin{aligned}
\frac{d y_{2}^{2}\left(x_{2}\right)}{d x_{2}^{2}} & =-C_{22} \beta^{2}+C_{24} \beta^{2}=0, \\
& \operatorname{or} C_{22}=C_{24} .
\end{aligned}
$$

Solving equations (22) and (23) simultaneously yields

$$
C_{22}=C_{24}=0 \text {. }
$$

Thus, equation (10) becomes

$$
y_{2}\left(x_{2}\right)=C_{21} \sin \beta x_{2}+C_{23} \sinh \beta x_{2} .
$$

(f) $y_{2}\left(x_{2}\right)=0$ at $x_{2}=L$, so equation (25) degenerates to

$$
\begin{gathered}
y_{2}\left(x_{2}=L\right)=C_{21} \sin \beta L+C_{23} \sinh \beta L=0, \\
\text { or } C_{23}=-\frac{\sin \beta L}{\sinh \beta L} C_{21} .
\end{gathered}
$$

\subsubsection{Boundary Conditions at the Interior Support}

Combining equations (11), (17), (18), and (21) and letting $x_{1}=L$ yields

$$
\begin{aligned}
\frac{d y_{1}\left(x_{1}=L\right)}{d x_{1}}= & C_{11} \beta \cos \beta L-C_{12} \beta \sin \beta L \\
& +C_{13} \beta \cosh \beta L+C_{14} \beta \sinh \beta L \\
= & C_{11} \beta(\cos \beta L-\cosh \beta L) \\
& -C_{12} \beta(\sin \beta L+\sinh \beta L) \\
= & 2 C_{11} \beta \frac{(1-\cos \beta L \cosh \beta L)}{(\cos \beta L-\cosh \beta L)} .
\end{aligned}
$$

Combining equations (14), (24), and (27) and letting $x_{2}=L$ yields

$$
\begin{aligned}
\frac{d y_{2}\left(x_{2}=L\right)}{d x_{2}} & =C_{21} \beta \cos \beta L+C_{23} \beta \cosh \beta L \\
& =-C_{21} \beta \frac{(\sin \beta L \cosh \beta L-\cos \beta L \sinh \beta L)}{\sinh \beta L} .
\end{aligned}
$$

Combining equations (12), (17), (18), and (21) and letting $x_{1}=L$ yields

$$
\begin{aligned}
\frac{d y_{1}^{2}\left(x_{1}=L\right)}{d x_{1}^{2}}= & -C_{11} \beta^{2} \sin \beta L-C_{12} \beta^{2} \cos \beta L \\
& +C_{13} \beta^{2} \sinh \beta L+C_{14} \beta^{2} \cosh \beta L \\
= & -C_{11} \beta^{2}(\sin \beta L+\sinh \beta L) \\
& -C_{12} \beta^{2}(\cos \beta L+\cosh \beta L) \\
= & 2 C_{11} \beta^{2} \frac{(\sin \beta L \cosh \beta L-\cos \beta L \sinh \beta L)}{(\cos \beta L-\cosh \beta L)} .
\end{aligned}
$$


Combining equations (15), (24), and (27) and letting $x_{2}=L$ yields

$$
\begin{aligned}
\frac{d y_{2}^{2}\left(x_{2}=L\right)}{d x_{2}^{2}} & =-C_{21} \beta^{2} \sin \beta L+C_{23} \beta^{2} \sinh \beta L \\
& =-2 C_{21} \beta^{2} \sin \beta L .
\end{aligned}
$$

(g) $d y_{1}\left(x_{1}=L\right) / d x_{1}=-d y_{2}\left(x_{2}=L\right) / d x_{2}$ at $x_{1}=x_{2}=L$, so combining equations (28) and (29) yields

$$
\begin{gathered}
2 C_{11} \beta \frac{(1-\cos \beta L \cosh \beta L)}{(\cos \beta L-\cosh \beta L)} \\
=C_{21} \beta \frac{(\sin \beta L \cosh \beta L-\cos \beta L \sinh \beta L)}{\sinh \beta L}, \\
\text { or } \frac{2(1-\cos \beta L \cosh \beta L)}{(\cos \beta L-\cosh \beta L)} C_{11} \\
-\frac{(\sin \beta L \cosh \beta L-\cos \beta L \sinh \beta L)}{\sinh \beta L} C_{21}=0 .
\end{gathered}
$$

(h) $d y_{1}^{2}\left(x_{1}=L\right) / d x_{1}=d y_{2}^{2}\left(x_{2}=L\right) / d x_{2}$ at $x_{1}=x_{2}=L$, so combining equations (30) and (31) yields

$$
\begin{aligned}
& 2 C_{11} \beta^{2} \frac{(\sin \beta L \cosh \beta L-\cos \beta L \sinh \beta L)}{(\cos \beta L-\cosh \beta L)} \\
& =-2 C_{21} \beta^{2} \sin \beta L, \\
& \text { or } \frac{(\sin \beta L \cosh \beta L-\cos \beta L \sinh \beta L)}{(\cos \beta L-\cosh \beta L)} C_{11}+\sin \beta L C_{21} \\
& =0 .
\end{aligned}
$$

A nontrivial solution for equations (33) and (35) exists only if the determinant of the coefficient matrix vanishes, which yields

$$
\begin{aligned}
& \frac{2(1-\cos \beta L \cosh \beta L) \sin \beta L}{(\cos \beta L-\cosh \beta L)} \\
& +\frac{(\sin \beta L \cosh \beta L-\cos \beta L \sinh \beta L)^{2}}{\sinh \beta L(\cos \beta L-\cosh \beta L)}=0 .
\end{aligned}
$$

Thus, the frequency equation can be obtained as

$$
(\sin \beta L+\sinh \beta L)^{2}-\sin 2 \beta L \sinh 2 \beta L=0 .
$$

Similarly, based on equation (7) and the boundary conditions for different two equal span flooring systems which are listed in Table 1, the frequency equations for other fifteen cases with two equal span floors and various end support conditions can be deduced, as illustrated in Table 2.

4.2. Modal Frequencies and Shapes. From the frequency equations, the modal frequencies for two equal span timber flooring systems can be obtained numerically. Here commercial software MathCAD is used for such purpose, and Table 3 illustrates the values of $\beta_{i} L$ for the first four modal frequencies of sixteen timber flooring systems with two equal spans and various boundary conditions. The symbol ${ }^{*}$ in Table 3 indicates the rigid mode for free-free boundary conditions.

The vibrational mode shapes only for the first modes of two equal span continuous floor beams with various boundary conditions are illustrated in Figures 3-6. Figure 3 illustrates the first vibrational modes for two equal span continuous timber floor beams with free left ends and various boundary conditions for right ends. All the mode shapes are not in scale. The left ends sustain free drops, and the right ends have various shapes which depend on predefined boundary conditions. At the interior support, the slopes of the mode shapes for both left and right spans are continuous. In general, the fundamental frequency parameter $\beta_{1} L$ increases in the following order for the right end boundary conditions: free, sliding, pinned, and fixed. It should be mentioned that the first vibrational mode for the free-free boundary conditions should be rigid with a zero modal frequency.

Figure 4 illustrates the first vibrational modes for two equal span continuous timber floor beams with sliding left ends and various boundary conditions for right ends. The left ends have zero slopes, and the right spans have various shapes which depend on predefined boundary conditions. The fundamental frequency parameter $\beta_{1} L$ increases in the same order for the right end boundary conditions: free, sliding, pinned, and fixed.

Figure 5 illustrates the first vibrational modes for two equal span continuous timber floor beams with pinned left ends and various boundary conditions for right ends. The left ends have zero displacements, and the right spans have various shapes which depend on predefined boundary conditions. The fundamental frequency parameter $\beta_{1} L$ increases in the same order for the right end boundary conditions: free, sliding, pinned, and fixed.

Finally, Figure 6 illustrates the first vibrational modes for two equal span continuous timber floor beams with fixed left ends and various boundary conditions for right ends. The left ends have zero displacement and slope, and the right spans have various shapes which depend on predefined boundary conditions. The fundamental frequency parameter $\beta_{1} L$ increases in the same order for the right end boundary conditions as mentioned above.

The shapes for higher modes are more complex and will not be discussed here further.

\section{Vibrations for Continuous Floors with Two Unequal Spans}

5.1. Frequency Equation. For continuous floors with two unequal spans $\left(L_{2}=\alpha L_{1}\right)$ and pinned end supports (Figure 7), the frequency equation can be obtained based on equation (7) and the boundary conditions in Table 1 for pinned ends. 
TABLE 2: Frequency equations for two-span beams with various end support conditions.

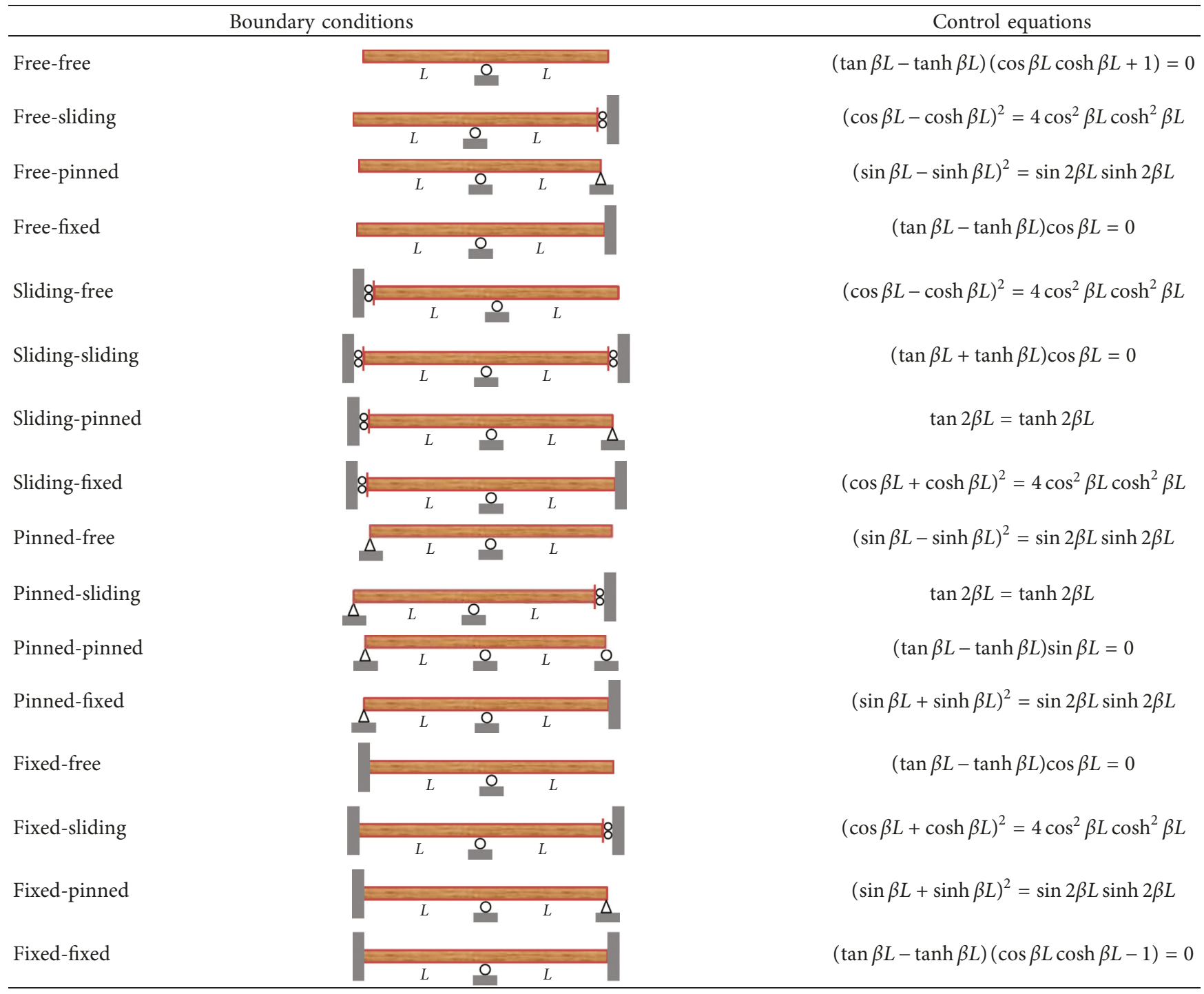

TABLE 3: Frequency parameters for two-span beams with various end support conditions.

\begin{tabular}{lcccc}
\hline Boundary conditions & $\beta_{1} L$ & $\beta_{2} L$ & $\beta_{3} L$ & $\beta_{4} L$ \\
\hline Free-free & $0.0000^{*}$ & 1.8751 & 3.9266 & 4.6941 \\
Free-sliding & 1.1705 & 2.1695 & 4.1798 & 5.2329 \\
Free-pinned & 1.5059 & 3.4131 & 4.4373 & 6.5446 \\
Free-fixed & 1.5708 & 3.9266 & 4.7124 & 7.0686 \\
Sliding-free & 1.1705 & 2.1695 & 4.1798 & 5.2329 \\
Sliding-sliding & 1.5708 & 2.3650 & 4.7124 & 5.4978 \\
Sliding-pinned & 1.9633 & 3.5343 & 5.1051 & 6.6759 \\
Sliding-fixed & 2.0295 & 4.1973 & 5.2391 & 7.3300 \\
Pinned-free & 1.5059 & 3.4131 & 4.4373 & 6.5446 \\
Pinned-sliding & 1.9633 & 3.5343 & 5.1051 & 6.6759 \\
Pinned-pinned & 3.1416 & 3.9266 & 6.2832 & 7.0686 \\
Pinned-fixed & 3.3932 & 4.4633 & 6.5454 & 7.5916 \\
Fixed-free & 1.5708 & 3.9266 & 4.7124 & 7.0686 \\
Fixed-sliding & 2.0295 & 4.1973 & 5.2391 & 7.3300 \\
Fixed-pinned & 3.3932 & 4.4633 & 6.5454 & 7.5916 \\
Fixed-fixed & 3.9266 & 4.7300 & 7.0686 & 7.8532 \\
\hline
\end{tabular}

\subsubsection{Boundary Conditions for Span 1}

(a) $y_{1}\left(x_{1}\right)=0$ at $x_{1}=0$, so equation (9) degenerates to

$$
\begin{gathered}
y_{1}\left(x_{1}=0\right)=C_{12}+C_{14}=0, \\
\text { or } C_{14}=-C_{12} .
\end{gathered}
$$

(b) $d y_{1}^{2}\left(x_{1}\right) / d x_{1}^{2}=0$ at $x_{1}=0$, so equation (12) degenerates to

$$
\begin{aligned}
\frac{d y_{1}^{2}\left(x_{1}\right)}{d x_{1}^{2}} & =-C_{12} \beta^{2}+C_{14} \beta^{2}=0, \\
\text { or } C_{12} & =C_{14} .
\end{aligned}
$$

Solving equations (38) and (39) simultaneously yields

$$
C_{12}=C_{14}=0 \text {. }
$$




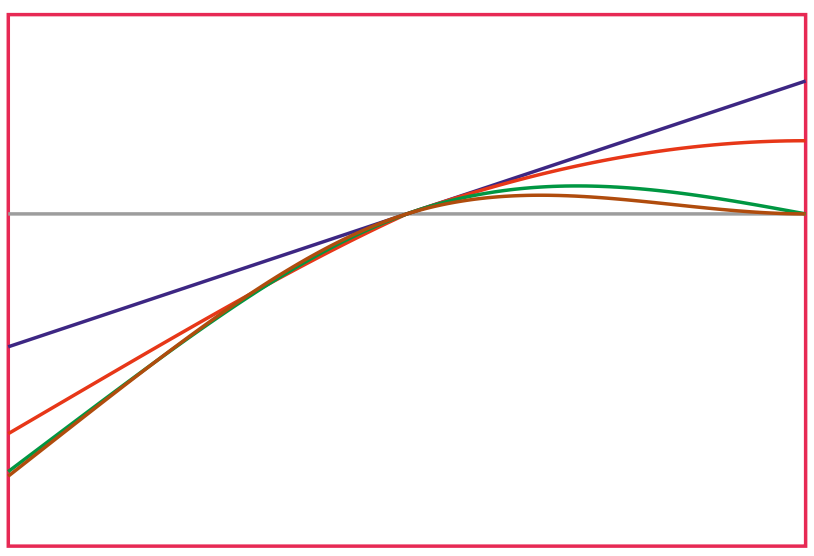

$\begin{array}{ll}\text { - Original position } & \text { Free-free } \\ \text { Free-sliding } & - \text { Free-pinned } \\ & \end{array}$

FIgURE 3: First vibrational modes for two equal span continuous timber floor beams with free left ends and various boundary conditions for right ends.

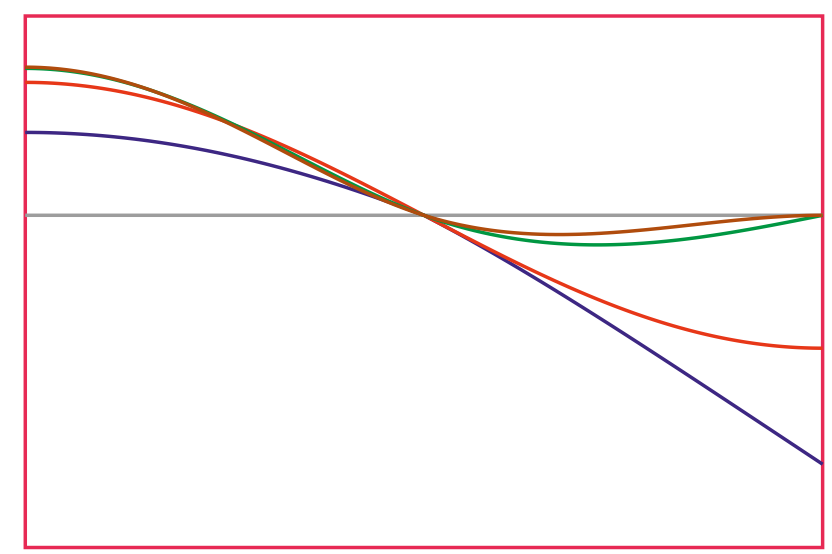

$\begin{array}{ll}\text { — Original position } & \text { - Sliding-pinned } \\ \text { Sliding-free } & \text { Sliding-fixed }\end{array}$

FIGURE 4: First vibrational modes for two equal span continuous timber floor beams with sliding left ends and various boundary conditions for right ends.

Thus, equation (9) becomes

$$
y_{1}\left(x_{1}\right)=C_{11} \sin \beta x_{1}+C_{13} \sinh \beta x_{1} .
$$

(c) $y_{1}\left(x_{1}\right)=0$ at $x_{1}=L_{1}$, so equation (41) degenerates to

$$
\begin{gathered}
y_{1}\left(x_{1}=L_{1}\right)=C_{11} \sin \beta L_{1}+C_{13} \sinh \beta L_{1}=0, \\
\text { or } C_{13}=-\frac{\sin \beta L_{1}}{\sinh \beta L_{1}} C_{11} .
\end{gathered}
$$

\subsubsection{Boundary Conditions for Span 2}

(d) $y_{2}\left(x_{2}\right)=0$ at $x_{2}=0$, so equation (10) degenerates to

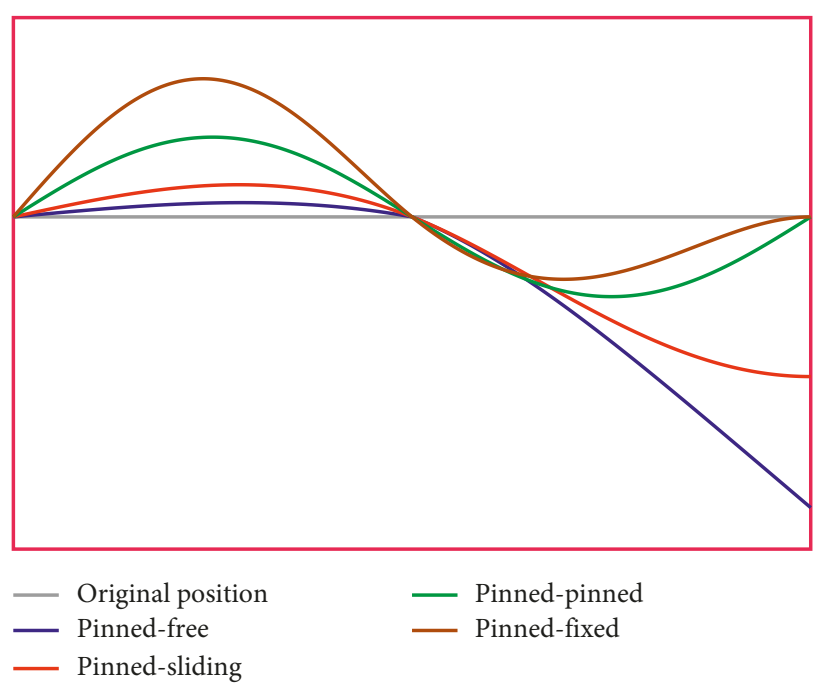

FIgURE 5: First vibrational modes for two equal span continuous timber floor beams with pinned left ends and various boundary conditions for right ends.

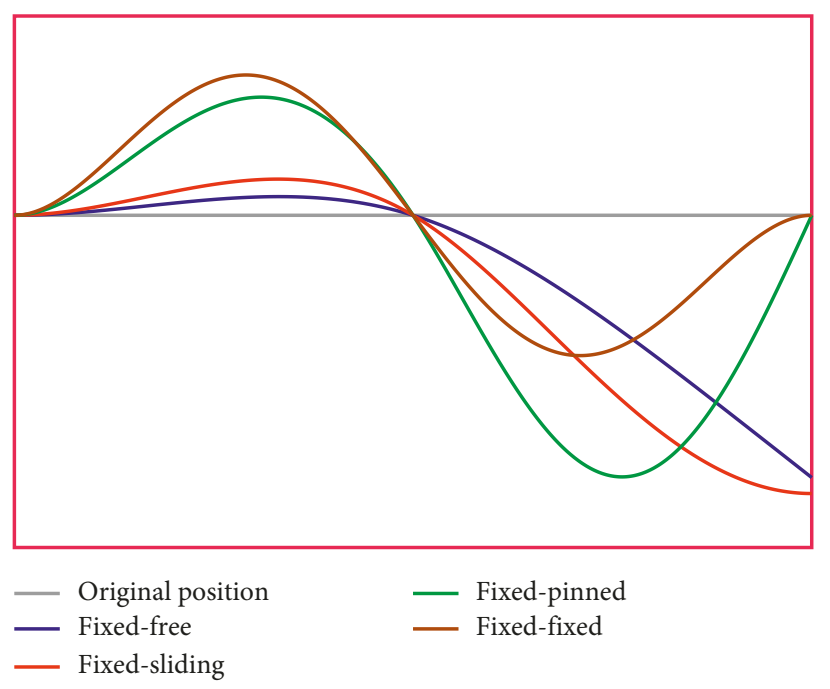

FIgURE 6: First vibrational modes for two equal span continuous timber floor beams with fixed left ends and various boundary conditions for right ends.

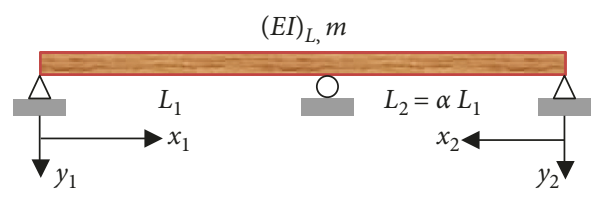

FIgURE 7: A continuous timber floor beam with two unequal spans and pinned-pinned end supports.

$$
\begin{gathered}
y_{2}\left(x_{2}=0\right)=C_{22}+C_{24}=0, \\
\text { or } C_{24}=-C_{22} .
\end{gathered}
$$

(e) $d y_{2}^{2}\left(x_{2}\right) / d x_{2}^{2}=0$ at $x_{2}=0$, so equation (15) degenerates to 


$$
\begin{aligned}
& \frac{d y_{2}^{2}\left(x_{2}\right)}{d x_{2}^{2}}=-C_{22} \beta^{2}+C_{24} \beta^{2}=0 \\
& \quad \text { or } C_{22}=C_{24} .
\end{aligned}
$$

Solving equations (44) and (45) simultaneously yields

$$
C_{22}=C_{24}=0 \text {. }
$$

Thus, equation (10) becomes

$$
y_{2}\left(x_{2}\right)=C_{21} \sin \beta x_{2}+C_{23} \sinh \beta x_{2} .
$$

(f) $y_{2}\left(x_{2}\right)=0$ at $x_{2}=L_{2}$, so equation (47) degenerates to

$$
\begin{gathered}
y_{2}\left(x_{2}=L_{2}\right)=C_{21} \sin \beta L_{2}+C_{23} \sinh \beta L_{2}=0, \\
\text { or } C_{23}=-\frac{\sin \beta L_{2}}{\sinh \beta L_{2}} C_{21} .
\end{gathered}
$$

\subsubsection{Boundary Conditions at the Interior Support}

Combining equations (11), (40), and (43) and letting $x_{1}=L_{1}$ yields

$$
\begin{aligned}
\frac{d y_{1}\left(x_{1}=L_{1}\right)}{d x_{1}} & =C_{11} \beta \cos \beta L_{1}+C_{13} \beta \cosh \beta L_{1} \\
& =-C_{11} \beta \frac{\left(\sin \beta L_{1} \cosh \beta L_{1}-\cos \beta L_{1} \sinh \beta L_{1}\right)}{\sinh \beta L_{1}} .
\end{aligned}
$$

Combining equations (14), (46), and (49) and letting $x_{2}=L_{2}$ yields

$$
\begin{aligned}
\frac{d y_{2}\left(x_{2}=L_{2}\right)}{d x_{2}} & =C_{21} \beta \cos \beta L_{2}+C_{23} \beta \cosh \beta L_{2} \\
& =-C_{21} \beta \frac{\left(\sin \beta L_{2} \cosh \beta L_{2}-\cos \beta L_{2} \sinh \beta L_{2}\right)}{\sinh \beta L_{2}} .
\end{aligned}
$$

Combining equations (12), (40), and (43) and letting $x_{1}=L_{1}$ yields

$$
\begin{aligned}
\frac{d y_{1}^{2}\left(x_{1}=L_{1}\right)}{d x_{1}^{2}} & =-C_{11} \beta^{2} \sin \beta L_{1}+C_{13} \beta^{2} \sinh \beta L_{1} \\
& =-2 C_{11} \beta^{2} \sin \beta L_{1} .
\end{aligned}
$$

Combining equations (15), (46), and (49) and letting $x_{2}=L_{2}$ yields

$$
\begin{aligned}
\frac{d y_{2}^{2}\left(x_{2}=L_{2}\right)}{d x_{2}^{2}} & =-C_{21} \beta^{2} \sin \beta L_{2}+C_{23} \beta^{2} \sinh \beta L_{2} \\
& =-2 C_{21} \beta^{2} \sin \beta L_{2} .
\end{aligned}
$$

(g) $d y_{1}\left(x_{1}=L_{1}\right) / d x_{1}=-d y_{2}\left(x_{2}=L_{2}\right) / d x_{2}$ at $x_{1}=L_{1}$ and $x_{2}=L_{2}$, so combining equations (50) and (51) yields

$$
\begin{aligned}
& -C_{11} \beta \frac{\left(\sin \beta L_{1} \cosh \beta L_{1}-\cos \beta L_{1} \sinh \beta L_{1}\right)}{\sinh \beta L_{1}} \\
& =C_{21} \beta \frac{\left(\sin \beta L_{2} \cosh \beta L_{2}-\cos \beta L_{2} \sinh \beta L_{2}\right)}{\sinh \beta L_{2}},
\end{aligned}
$$

$$
\text { or } \begin{gathered}
\frac{\left(\sin \beta L_{1} \cosh \beta L_{1}-\cos \beta L_{1} \sinh \beta L_{1}\right)}{\sinh \beta L_{1}} C_{11} \\
+\frac{\left(\sin \beta L_{2} \cosh \beta L_{2}-\cos \beta L_{2} \sinh \beta L_{2}\right)}{\sinh \beta L_{2}} C_{21}=0 .
\end{gathered}
$$

(h) $d y_{1}^{2}\left(x_{1}=L_{1}\right) / d x_{1}=d y_{2}^{2}\left(x_{2}=L_{2}\right) / d x_{2}$ at $x_{1}=L_{1}$ and $x_{2}=L_{2}$, so combining equations (52) and (53) yields

$$
-2 C_{11} \beta^{2} \sin \beta L_{1}=-2 C_{21} \beta^{2} \sin \beta L_{2}
$$

$$
\text { or }-\sin \beta L_{1} C_{11}+\sin \beta L_{2} C_{21}=0 \text {. }
$$

A nontrivial solution for equations (55) and (57) exists only if the determinant of the coefficient matrix vanishes, which yields

$$
\begin{aligned}
& \frac{\left(\sin \beta L_{1} \cosh \beta L_{1}-\cos \beta L_{1} \sinh \beta L_{1}\right)}{\sinh \beta L_{1}} \sin \beta L_{2} \\
& +\frac{\left(\sin \beta L_{2} \cosh \beta L_{2}-\cos \beta L_{2} \sinh \beta L_{2}\right)}{\sinh \beta L_{2}} \sin \beta L_{1}=0,
\end{aligned}
$$

$$
\text { or } \begin{aligned}
\frac{\left(\sin \beta L_{1} \cosh \beta L_{1}-\cos \beta L_{1} \sinh \beta L_{1}\right)}{\sin \beta L_{1} \sinh \beta L_{1}} \\
+\frac{\left(\sin \beta L_{2} \cosh \beta L_{2}-\cos \beta L_{2} \sinh \beta L_{2}\right)}{\sin \beta L_{2} \sinh \beta L_{2}}=0 .
\end{aligned}
$$

Thus, the frequency equation can be obtained as

$$
\left(\cot \beta L_{1}-\operatorname{coth} \beta L_{1}\right)+\left(\cot \beta L_{2}-\operatorname{coth} \beta L_{2}\right)=0 \text {. }
$$

5.2. Model Frequencies and Shapes. From the frequency equations (58), (59), and (60), the modal frequencies of timber flooring systems with two unequal spans and pinned end supports for various span ratios can be obtained numerically. Again, commercial software MathCAD is used for such purpose, and Table 4 illustrates the values of $\beta_{i} L$ for the first four modal frequencies of timber flooring systems with eleven typical floor span ratios $\alpha=L_{2} / L_{1}$ between 0 and 1 . Figure 8 shows the fundamental vibrational mode shapes for $\alpha=0.00001,0.2,0.4,0.6,0.8$, and 1.0 , respectively.

When $\alpha=L_{2} / L_{1}$ is very small, e.g., 0.00001 , the mode shape for the left span approaches to the shape for a single 
TABLE 4: Frequency parameters for continuous beams with two unequal spans and pinned-pinned end supports.

\begin{tabular}{lcccc}
\hline$\alpha=L_{2} / L_{1}$ & $\beta_{1} L$ & $\beta_{2} L$ & $\beta_{3} L$ & $\beta_{4} L$ \\
\hline 0.00001 & 3.9266 & 7.0686 & 10.2101 & 13.3517 \\
0.01 & 3.9137 & 7.0456 & 10.1774 & 13.3093 \\
0.10 & 3.8143 & 6.8839 & 9.9647 & 13.0537 \\
0.20 & 3.7298 & 6.7630 & 9.8118 & 12.8402 \\
0.25 & 3.6947 & 6.7132 & 9.7294 & 12.5664 \\
0.40 & 3.6070 & 6.5443 & 8.6517 & 10.1140 \\
0.50 & 3.5564 & 6.2832 & 7.4295 & 9.8488 \\
0.60 & 3.5060 & 5.6983 & 6.9143 & 9.6741 \\
0.75 & 3.4167 & 4.7872 & 6.6908 & 8.7697 \\
0.80 & 3.3785 & 4.5499 & 6.6399 & 8.3275 \\
1.00 & 3.1416 & 3.9266 & 6.2832 & 7.0686 \\
\hline
\end{tabular}

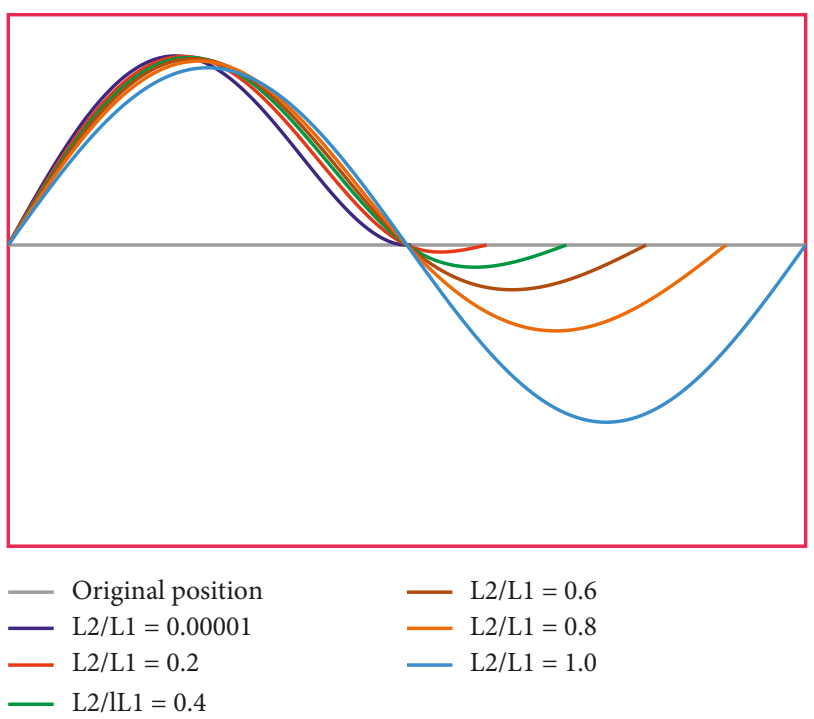

FIgURE 8: First vibrational modes for two unequal span continuous timber floor beams with pinned ends.

span beam with pinned left end and fixed right end, and the fundamental modal frequency is the largest. The corresponding amplitude for the right span is very small. With the increase in $\alpha$ value, the fundamental vibrational frequency $f_{1}$ decreases and the mode shape for the right span which always follows a half sine wave becomes more extended with higher amplitude. When $\alpha=1.0$, a full sine curve is obtained for the whole two equal span beam. This trend continues for $\alpha$ larger than 1.0. For this case, however, the right span can be treated as $L_{1}$ and the left span treated as $L_{2}$, so the same calculations can be conducted. At the interior support, the slopes of the mode shapes for both left and right spans are continuous.

5.3. Empirical Equations for Practical Design. Figure 9 illustrates that for $\alpha=0.0$ to 1.0 , a cubic relationship between the frequency parameter $\beta_{1} L$ and the span ratio $\alpha$ can be established empirically with the linear regression coefficient $R^{2}=0.9999$ as

$$
\beta_{1} L_{1}=-1.2134 \alpha^{3}+1.7213 \alpha^{2}-1.2910 \alpha+3.9266 .
$$

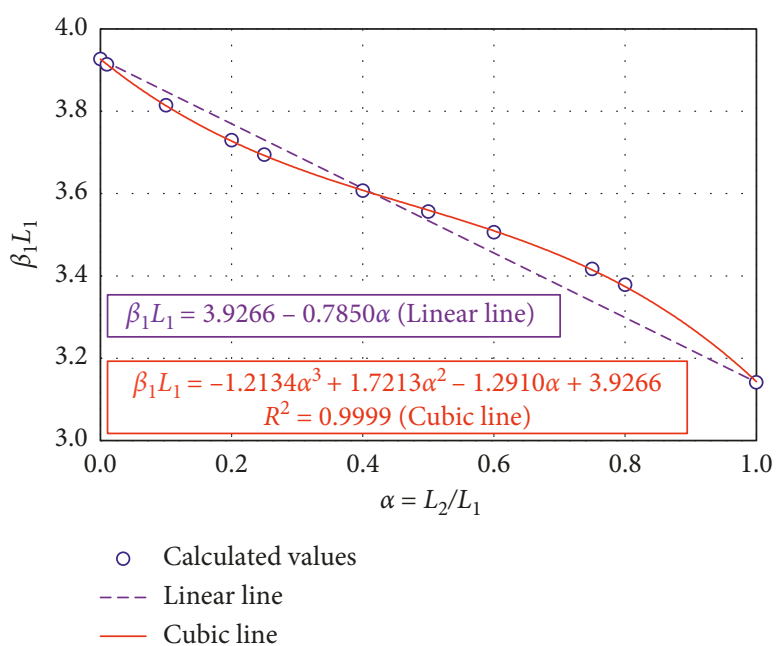

FIgURE 9: Relationships between $\beta_{1} L_{1}$ and $\alpha=L_{2} / L_{1}$ with the trendlines for $\alpha=0.0$ to 1.0 .

This equation can be used to determine the fundamental vibrational frequency, $f_{1}$, of continuous timber floors with two unequal spans for practical serviceability design as soon as the span ratio $\alpha$ is known.

Sometimes, a linear relationship between $\beta_{1} L_{1}$ and $\alpha=$ $L_{2} / L_{1}$ can be more convenient for practical engineers to quickly estimate the fundamental frequency of a timber floor. Here, only the values of $\beta_{1} L_{1}$ for $\alpha=0$ and 1.0 are used to form a simple linear empirical equation as follows without large errors from the accurate values (Figure 9):

$$
\beta_{1} L_{1}=3.9266-0.7850 \alpha \text {. }
$$

\section{Design Examples}

6.1. Two Equal Span Floor with Solid Timber Joists for FixedPinned Ends. A two-span timber floor is designed for a domestic timber frame building. It is constructed with continuous solid timber joists (Figure 10). The floor has a width $B=5.0 \mathrm{~m}$ and a length $L_{1}=L_{2}=4.8 \mathrm{~m}$ for each span. It is constructed with $75 \mathrm{~mm} \times 220 \mathrm{~mm}$ C24 solid timber joists at a spacing $s=600 \mathrm{~mm}$. The P5 particleboard with a thickness of $22 \mathrm{~mm}$ is chosen for the decking, and the Gyproc plasterboard with a thickness of $12.5 \mathrm{~mm}$ is chosen for the ceiling. The total self-weight of the flooring system including the timber joists is assumed to be $60 \mathrm{~kg} / \mathrm{m}^{2}$, and Service Class 2 is assumed. The imposed load is $Q_{\mathrm{k}}=1.5 \mathrm{kN} /$ $\mathrm{m}^{2}$ from EN 1991-1-1 [37].

From equation (8), the fundamental frequency $f_{1}$ can be determined as

$$
\begin{aligned}
f_{1} & =\frac{\left(\beta_{1} L_{1}\right)^{2}}{2 \pi L_{1}^{2}} \sqrt{\frac{(E I)_{L}}{m}}=\frac{3.3932^{2}}{2 \pi \times 4.8^{2}} \sqrt{\frac{1.2201 \times 10^{6}}{60}} \\
& =11.342 \mathrm{~Hz}>8 \mathrm{~Hz} \text { (design is satisfactory to the code!), }
\end{aligned}
$$

where $\beta_{1} L_{1}$ is the frequency parameter for the first mode and $\beta_{1} L=3.3932$ (quoted from Table 3), $L_{1}$ is the left span length 


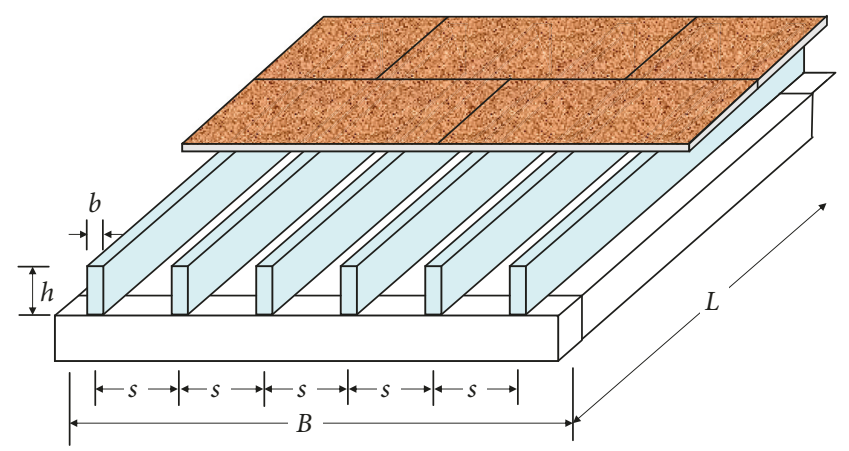

(a)

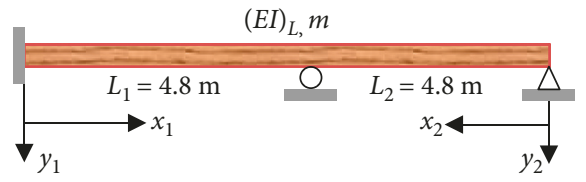

(b)

Figure 10: A two-span floor constructed from solid timber joists with fixed left end and pinned right end. (a) A two-span floor constructed with solid timber joists. (b) A two-span floor with fixed left end and pinned right end.

of the floor and $L_{1}=4.8 \mathrm{~m}, L_{2}$ is the right span length of the floor and $L_{2}=4.8 \mathrm{~m}, b$ is the width of the solid timber joist and $b=75 \mathrm{~mm}, h$ is the depth of the solid timber joist and $h=220 \mathrm{~mm}, E$ is the elastic modulus for C24 timber and $E=11 \mathrm{GPa}$ [38], $I$ is the second moment of area for a C24 timber joist and $I=b h^{3} / 12=0.075 \times 0.22^{3} / 12=66.55 \times$ $10^{-6} \mathrm{~m}^{4},(E I)_{L}$ is the equivalent plate bending stiffness of the timber floor about an axis perpendicular to the joist direction and $(E I)_{L}=E I / s=11 \times 10^{9} \times 66.55 \times 10^{-6} / 0.6=1.2201 \times$ $10^{6} \mathrm{Nm}^{2} / \mathrm{m}, s$ is the floor joist spacing and $s=0.6 \mathrm{~m}$, and $m$ is the floor mass per unit area and $m=60 \mathrm{~kg} / \mathrm{m}^{2}$.

6.2. Two Unequal Span Floor with I-Joists for Pinned-Pinned Ends. A two-span timber floor is designed for an office timber frame building. It has a width $B=6.0 \mathrm{~m}$, together with lengths $L_{1}=7.3 \mathrm{~m}$ and $L_{2}=2.92 \mathrm{~m}$ for left and right spans, which gives a span ratio $\alpha=L_{2} / L_{1}=2.92 / 7.3=0.4$. It is constructed with the engineered $I$-joists (JJI joists) produced by James Jones \& Sons Ltd in the UK [39] (Figure 11). The top and bottom flanges are manufactured from $\mathrm{C} 24$ solid timber with the width $b$ ranging from $47 \mathrm{~mm}$ to $97 \mathrm{~mm}$ (A to D) and a constant height of $h_{\mathrm{f}}=45 \mathrm{~mm}$. The web is manufactured from $9 \mathrm{~mm}$ OSB3 which is embedded into the flanges by $12 \mathrm{~mm}$. The $22 \mathrm{~mm}$ P5 particleboard is chosen for the decking, and the Gyproc plasterboard with a thickness of $12.5 \mathrm{~mm}$ is chosen for the ceiling. The total self-weight of the flooring system including the engineered $I$-joists is assumed to be $75 \mathrm{~kg} / \mathrm{m}^{2}$, and also Service Class 2 is assumed. The imposed load is taken as $Q_{\mathrm{k}}=2.5 \mathrm{kN} / \mathrm{m}^{2}$ [37]. The adopted JJI joists for this study are JJI $400 \mathrm{D}$ joists at a spacing $s=300 \mathrm{~mm}$ and with an overall joist depth $h=400 \mathrm{~mm}$.

From equation (8), the fundamental frequency $f_{1}$ can be determined as

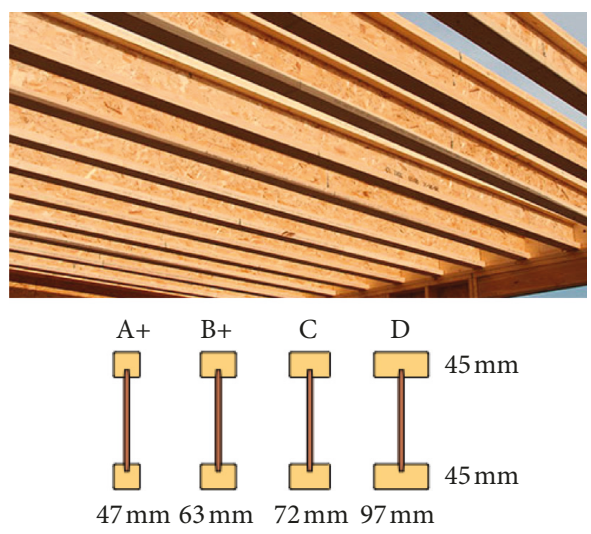

(a)

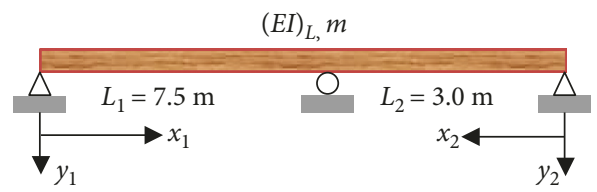

(b)

FIgURE 11: A two unequal span floor constructed from $I$-joists with pinned ends. (a) A two unequal span floor constructed with JJI $400 \mathrm{D}$ joists. (b) A two unequal span floor with pinned ends and $\alpha=0.4$.

$$
\begin{aligned}
f_{1} & =\frac{\left(\beta_{1} L_{1}\right)^{2}}{2 \pi L_{1}^{2}} \sqrt{\frac{(E I)_{L}}{m}}=\frac{3.6070^{2}}{2 \pi \times 7.5^{2}} \sqrt{\frac{10.3930 \times 10^{6}}{75}} \\
& =13.703 \mathrm{~Hz}>8 \mathrm{~Hz} \text { (design is satisfactory to the code!), }
\end{aligned}
$$

where $\beta_{1} L_{1}$ is the frequency parameter for the first mode and $\beta_{1} L=3.6070$ (quoted from Table 4), $L_{1}$ is the left span length of the floor and $L_{1}=7.5 \mathrm{~m}, L_{2}$ is the right span length of the floor and $L_{2}=3.0 \mathrm{~m}, \alpha$ is the span ratio and $a=L_{2} / L_{1}=3.0 /$ $7.5=0.4, b$ is the width of the solid timber flanges of JJI $400 \mathrm{D}$ joists and $b=97 \mathrm{~mm}, h_{\mathrm{f}}$ is the depth of the solid timber flanges of JJI $400 \mathrm{D}$ joists and $h=45 \mathrm{~mm}, t_{\mathrm{w}}$ is the thickness of the OSB3 web of JJI 400D joists and $t_{\mathrm{w}}=9 \mathrm{~mm}, h$ is the overall depth of JJI $400 \mathrm{D}$ joists and $h=400 \mathrm{~mm}, E$ is the elastic modulus for $\mathrm{C} 24$ timber and $E=11 \mathrm{GPa}$ [38], $E_{\mathrm{P} 5}$ is the mean elastic modulus for $9 \mathrm{~mm}$ OSB3 web and $E_{\mathrm{P} 5}=$ $3000 \mathrm{MPa}, I$ is the equivalent second moment of area with respect to $\mathrm{C} 24$ solid timber for a JJI $400 \mathrm{D}$ joist and $I=2.8345 \times 10^{-4} \mathrm{~m}^{4},(E I)_{L}$ is the same as above and $(E I)_{L}=$ $E I / s=11 \times 10^{9} \times 2.8345 \times 10^{-4} / 0.3=10.3932 \times 10^{6} \mathrm{Nm}^{2} / \mathrm{m}, \quad s$ is the floor joist spacing and $s=0.3 \mathrm{~m}$, and $m$ is the floor mass per unit area and $m=75 \mathrm{~kg} / \mathrm{m}^{2}$.

\section{Conclusions}

Based on classic vibrational bending theory on beams, comprehensive analytical formulae for dynamic characteristics of two-span continuous timber flooring systems have been established, including frequency equations, modal frequencies, and mode shapes. Four practical boundary 
conditions are considered for end supports, including free, sliding, pinned, and fixed supports, and a total of sixteen combinations of flooring systems are created.

The characteristic equations for modal frequencies of two equal span continuous beams with various boundary conditions have been deduced, and four sets of mode shapes have been illustrated. A rigid mode exists for free-free end boundary conditions. A full example for fixed-pinned boundary conditions has been presented to show the deduction procedure.

The characteristic equations for modal frequencies of two unequal span continuous beams with pinned-pinned end conditions have been deduced, and one set of the corresponding mode shapes for various span ratios has been illustrated. A full example for pinned-pinned boundary conditions with a general span ratio has been presented to show the deduction procedure. Also, two empirical equations, cubic and linear, for determining the modal frequency parameters with respect to varying span ratios have been proposed and can be used directly for practical design.

Finally, two practical design examples for determining fundamental modal frequencies have been presented, one for a two equal span continuous floor constructed with solid timber joists and fixed-pinned ends and the other for a two unequal span continuous floor constructed with JJI 400D Ijoists pinned at both ends.

\section{Data Availability}

The data used in this study will be deposited in a repository.

\section{Disclosure}

Part of the work was presented at World Conference on Timber Engineering (WCTE 2016), 22-25 August 2016 in Vienna, Austria.

\section{Conflicts of Interest}

The authors declare that they have no conflicts of interest.

\section{Acknowledgments}

The assistance of Dr. Martin Cullen toward this paper is highly appreciated.

\section{References}

[1] British Standards Institution, BS EN 1995-1-1: $2004+A 1$ : 2008 Eurocode 5: Design of Timber Structures, Part 1-1: General-Common Rules and Rules for Buildings, British Standards Institution, London, UK, 2004.

[2] British Standards Institution, BS EN 1990:2002 \pm A1:2005 Eurocode-Basis of Structural Design, British Standards Institution, London, UK, 2002.

[3] B. Zhang, B. Rasmussen, A. Jorissen, and A. Harte, "Comparison of vibrational comfort assessment criteria for design of timber floors among the European countries," Engineering Structures, vol. 52, pp. 592-607, 2013.
[4] S. V. Ohlsson, Floor vibrations and human discomfort, Ph.D. thesis, Chalmers University of Technology, Gothenburg, Sweden, 1982.

[5] Y. H. Chui, Vibrational performance of wooden floors in domestic dwellings, Ph.D. thesis, Brighton Polytechnic, Brighton, UK, 1987.

[6] L. J. Hu, Prediction of vibration responses of ribbed plates by modal synthesis, Ph.D. thesis, The University of New Brunswick, New Brunswick, Canada, 1992.

[7] P. E. Eriksson, Vibration of low-frequency floors-dynamic forces and response prediction, Ph.D. thesis, Chalmers University of Technology, Göteborg, Sweden, 1994.

[8] I. Smith, "Vibrations of timber floors: serviceability aspects," in Timber Engineering, S. Thelandersson and H. J. Larsen, Eds., pp. 241-266, John Wiley \& Sons, Hoboken, NJ, USA, 2003.

[9] A. Bahadori-Jahromi, A. Kermani, B. Zhang et al., "Influence of geometrical profiles on the structural properties of engineered composite timber beams," Proceedings of the Institution of Civil Engineers-Structures and Buildings, vol. 159, no. 2, pp. 103-114, 2006.

[10] A. Bahadori-Jahromi, B. Zhang, A. Harte, B. Walford, K. Bayne, and J. Turner, "Investigating the structural performance of multi-webs I-beams," Journal of the Institute of Wood Science, vol. 17, no. 3, pp. 148-158, 2006.

[11] A. Homb, Low frequency sound and vibrations from impacts on timber floor constructions, Ph.D. thesis, Norwegian University of Science and Technology, Trondheim, Norway, 2006.

[12] F. Ljunggren, Floor vibration-dynamic properties and subjective perception, Ph.D. thesis, Lulea University of Technology, Lulea, Sweden, 2006.

[13] T. Toratti and A. Talja, "Classification of human induced floor vibrations," Building Acoustics, vol. 13, no. 3, pp. 211-221, 2006.

[14] B. Zhang, A. Bahadori-Jahromi, and A. Kermani, "Influence of EC5 and the UK National Annex on the design of timber flooring systems built with multi-webbed engineered joists and solid timber joists," Technical Document for BSI Technical Committee B/525/5, British Standards Institution, London, UK, 2005.

[15] A. Bahadori-Jahromi, A. Kermani, B. Zhang, and D. Reid, “A parametric evaluation of multi-webbed composite joists based on EC5," Journal of the Institute of Wood Science, vol. 17, no. 6, pp. 295-310, 2007.

[16] J. Weckendorf, Dynamic response of structural timber flooring systems, Ph.D. thesis, Edinburgh Napier University, Edinburgh, UK, 2009.

[17] N. Labonnote, Damping in timber structures, Ph.D. thesis, Norwegian University of Science and Technology, Trondheim, Norway, 2012.

[18] B. Zhang, A. Kermani, and T. Fillingham, "Vibrational performance of timber floors constructed with metal web joists," Engineering Structures, vol. 56, pp. 1321-1334, 2013.

[19] B. Zhang, A. Kermani, and T. Fillingham, "Vibrations of metal web joist timber floors with strongbacks," Proceedings of the Institution of Civil Engineers-Structures and Buildings, vol. 169, no. 8, pp. 549-562, 2016.

[20] K. Jarnerö, A. Brandt, and A. Olsson, "Vibration properties of a timber floor assessed in laboratory and during construction," Engineering Structures, vol. 82, pp. 44-54, 2015.

[21] W. M. C. McKenzie abd and B. Zhang, Design of Structural Timber to Eurocode 5, Palgrave MacMillan, Basingstoke, UK, 2nd edition, 2007. 
[22] J. Porteous and A. Kermani, Structural Timber Design to Eurocode 5, Wiley-Blackwell, Hoboken, NJ, USA, 2nd edition, 2013.

[23] B. Basaglia, R. Shrestha, K. Crews, and Y. Yokoyama, "Vibration response of a long-span LVL floor: comparison between Japanese and Australian assessment measures," in Proceedings of the World Conference on Timber Engineering 2018 (WCTE-2018), Seoul, Republic of Korea, August 2018.

[24] M. M. Ebadi, T. Tannert, G. Doudak, and I. Smith, "Vibration behaviour of glulam beam and deck floors," in Proceedings of the World Conference on Timber Engineering 2018 (WCTE-2018), Seoul, Republic of Korea, August 2018.

[25] C. Ui Chulain and A. M. Harte, "“"Experimental investigation of the serviceability behaviour of a cross laminated timber floor," in Proceedings of the Civil Engineering Research in Ireland Conference CERI-ITRN 2018, Dublin, Ireland, August 2018.

[26] Y. Koyama, H. Matsushita, S. Fukuda, and Y. Yokoyama, "Measurement about walking vibration on cross laminated timber floors, and presentation of a span table by finite element method," in Proceedings of the World Conference on Timber Engineering 2018 (WCTE-2018), Seoul, Republic of Korea, August 2018.

[27] T. A. Bui, M. Oudjene, P. Lardeur, M. Khelifa, and Y. Rogaume, "Vibration performance of ahesive free multilayered timber beams assembled through compressed wood dowels," in Proceedings of the World Conference on Timber Engineering 2018 (WCTE-2018), Seoul, Republic of Korea, August 2018.

[28] F. Lanata, C. Boudaud, and K. V. Amouzou, "Guidelines definition for in-situ vibration measurements of buildings," in Proceedings of the World Conference on Timber Engineering 2018 (WCTE-2018), Seoul Republic of Korea, August 2018.

[29] British Standards Institution, UK NA to BS EN 1995-1-1:2004 + A1: 2008 UK National Annex to Eurocode 5: Design of Timber Structures-Part 1-1: General-Common Rules and Rules for Buildings, British Standards Institution, London, UK, 2009.

[30] Österreichisches Normungsinstitut, ÖNORM B EN 1995-1-1/ NA Austrian National Annex to Eurocode 5: Design of Timber Structures-Part 1-1: General-Common Rules and Rules for Buildings, Österreichisches Normungsinstitut, Vienna, Austria, 2009.

[31] Suomen Standardisoimisliitto, FIN NA to SFS EN 1995-1-1: 2004 + A1:2008 Finnish National Annex to Eurocode 5: Design of Timber Structures-Part 1-1: General-Common Rules and Rules for Buildings, Suomen Standardisoimisliitto, Helsinki, Finland, 2007.

[32] Asociación Española de Normalización y Certificación, Document N 244 Spanish National Annex to Eurocode 5: Design of Timber Structures-Part 1-1: General-Common Rules and Rules for Buildings, Asociación Española de Normalización y Certificación, Madrid, Spain, 2010.

[33] L. J. Hu, Y.-H. Chui, P. Hamm, T. Toratti, and T. Orskaug, "Development of ISO baseline vibration design method for timber floors," in Proceedings of the World Conference on Timber Engineering 2018 (WCTE-2018), Seoul, Republic of Korea, August 2018.

[34] Y. Wang, Q. Wei, J. Shi, and X. Long, "Resonance characteristics of two-span continuous beam under moving high speed trains," Latin American Journal of Solids and Structures, vol. 7, no. 2, pp. 185-199, 2010.

[35] A. Mahapatra and A. Chatterjee, "Comparison of analytical and numerical results in model analysis of multispan continuous beams with LS-DYNA ${ }^{\circledR}$," in Proceedings of the 10th International LS-DYNA ${ }^{\circledR}$ Users Conference, Dearborn, MI, USA, June 2008

[36] J. W. Tedesco, W. G. McDougal, and C. A. Ross, Structural Dynamics: Theory and Applications, Addison-Wesley, San Francisco, CA, USA, 1998.

[37] British Standards Institution, BS EN 1991-1-1 Eurocode 1: Actions on Structures-Part 1-1: General Actions-Densities, Self-Weight, Imposed Loads for Buildings, British Standards Institution, London, UK, 2002.

[38] British Standards Institution, BS EN 338: Structural Timber-Strength Classes, British Standards Institution, London, UK, 2016.

[39] James Jones \& Sons Ltd., JJI-Joists-Technical Manual, James Jones \& Sons Ltd., Forres, Scotland, UK, 2012. 


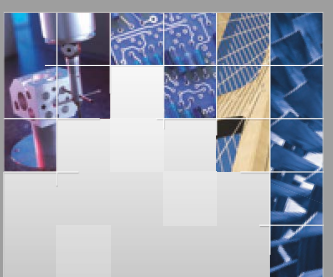

\section{Enfincering}
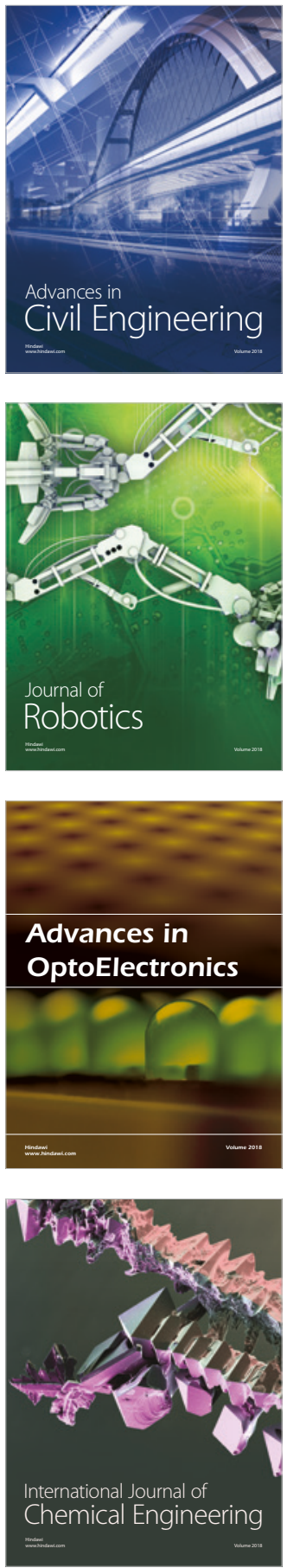

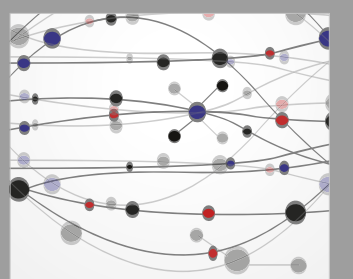

\section{Rotating \\ Machinery}

The Scientific World Journal

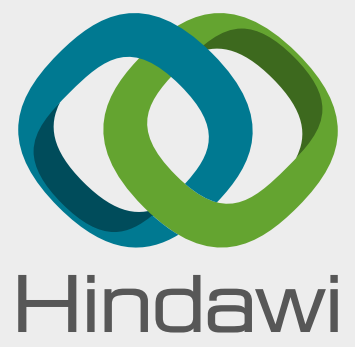

Submit your manuscripts at

www.hindawi.com
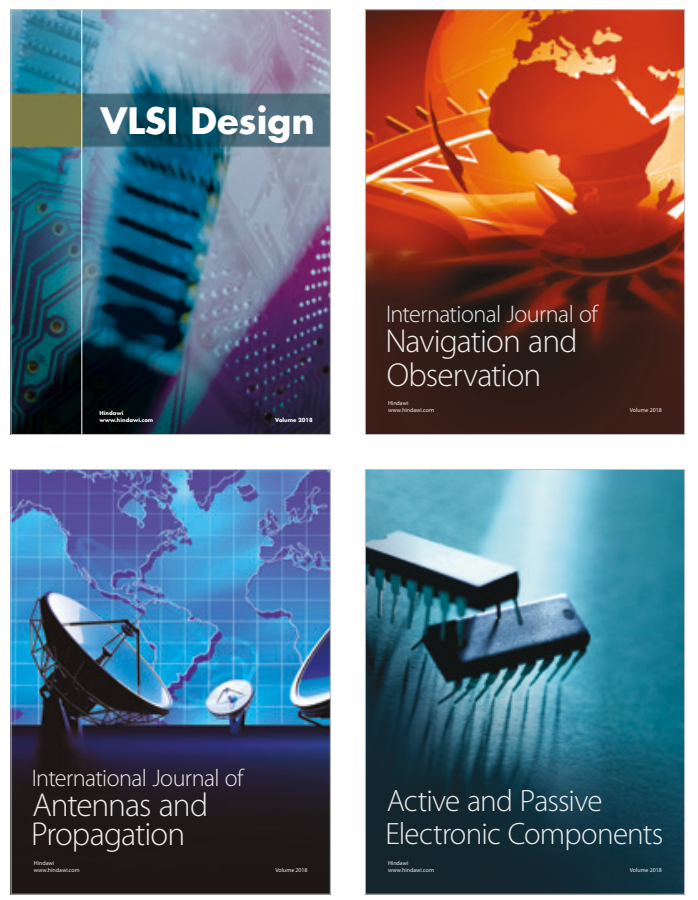
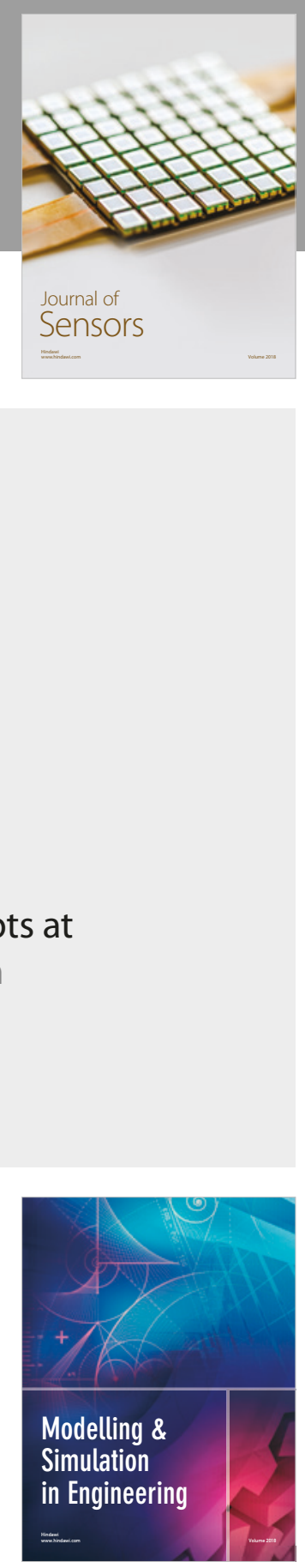

\section{Advances \\ Multimedia}
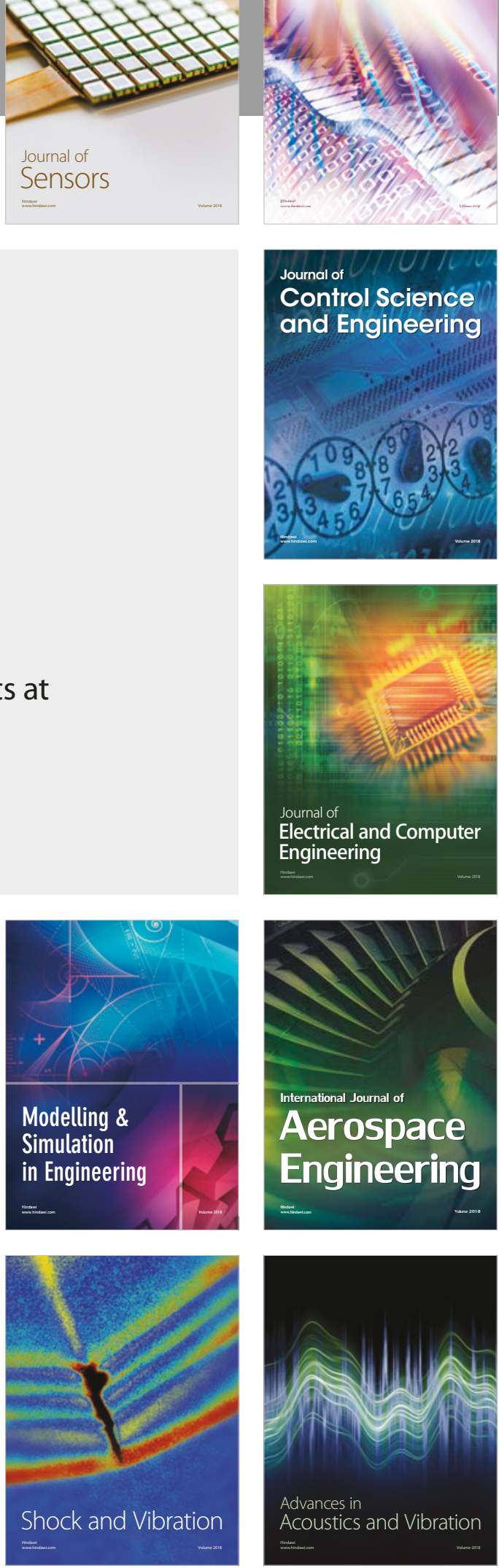